\title{
Segment-Specific Morphogenesis of Leech Retzius Neurons Requires Particular Peripheral Targets
}

\author{
Curtis M. Loer, John Jellies, and William B. Kristan, Jr. \\ Department of Biology, University of California, San Diego, La Jolla, California 92093
}

In most segments of the leech, a pair of Retzius (Rz) cells innervate the body wall musculature and skin; however, in the segments specialized for reproduction (midbody segments 5 and 6 ), these neurons innervate the reproductive tissue instead. Whereas all Rz cells have the same morphology early in embryogenesis, those in the reproductive segments $[R z(5,6)]$ become considerably different from their segmental homologs. Unlike standard $R z$ cells, $R z(5,6)$ do not have axons in the interganglionic connectives or in the body wall (Glover and Mason, 1986). Rz(5,6) also have significantly smaller somata and fewer branches in the ganglionic neuropil than do standard Rz cells (Jellies et al., 1987). Since these differences between $R z$ cells do not become apparent until after $R z(5,6)$ processes appear to contact the reproductive tissue primordia, interactions between $\operatorname{Rz}(5,6)$ processes and the reproductive tissue may determine the segmental specializations of these neurons.

We have tested this possibility by ablating the reproductive tissue primordia early in embryogenesis and subsequently examining $R z(5,6)$ morphology. In the absence of reproductive tissue, $R z(5,6)$ became more like standard $R z$ cells: they retained axons in the interganglionic connectives, they projected into the body wall, and the density of their arborization within the neuropil increased. These results indicate that the development of some segmental specializations of $\operatorname{Rz}(5,6)$ involves an interaction with their unique target tissue.

Individual cells in invertebrates often seem to exhibit a high degree of autonomy in their acquisition of phenotype. For example, in Drosophila a single cuticle cell made "male" by somatic recombination will develop its male phenotype completely surrounded by "female" cells (Baker and Ridge, 1980). There are exceptions to this extreme cell autonomy, many of which are found among cells of the nervous system (Chalfie et al., 1983; Doe and Goodman, 1985; Stuart et al., 1987). This is perhaps not surprising since neurons must find and connect with specific targets and may act as guides and specific targets themselves (Lopresti et al., 1973; Bentley and Keshishian, 1982; Ho and Goodman, 1982; Raper et al., 1983; Kuwada, 1986). Thus,

\footnotetext{
Received Feb. 7, 1987; revised Apr. 7, 1987; accepted Apr. 10, 1987.

We wish to thank S. Reynolds and S. Furgal for technical assistance, and J. Juni of Invention Software, Inc. and M. Friedman for discussions helpful in software development. This work was supported by NIH Research Grant NS20746 to W.B.K., NIH Postdoctoral Fellowship NS07684 to J.J., and NIH Predoctoral Traineeship GM07313 to C.M.L.

Correspondence should be addressed to Curtis M. Loer, Department of Biology, B-022, University of California, San Diego, La Jolla, CA 92093.

Copyright (C) 1987 Society for Neuroscience $0270-6474 / 87 / 092630-09 \$ 02.00 / 0$
}

the interaction of a neuron with a target during development may be important in determining some of its characteristics. In the previous report (Jellies et al., 1987), we described and quantified the development of segmental differences in the morphology of the Retzius neurons in the leech Hirudo medicinalis. In this report, we present evidence that the morphogenesis of these identified neurons is strongly influenced by the tissue they contact during embryogenesis.

In most scgments of the lccch, the 2 Retzius ( $\mathrm{Rz}$ ) cclls innervate the body wall musculature and skin; however, in the segments specialized for reproduction, these neurons $[\operatorname{Rz}(5,6)]$ innervate the reproductive tissue. Furthermore, $\mathrm{Rz}(5,6)$ do not have axons in the interganglionic connectives (Glover and Mason, 1986), have significantly smaller somata, and less dense arborization in the ganglionic neuropil than do standard $\mathrm{Rz}$ cells (Jellies et al., 1987). [Glover (1987) has described similar segmental differences between some morphological characteristics of standard $\mathrm{Rz}$ cells and $\mathrm{Rz}(5,6)$ in the glossiphonoiid leech Haementeria ghilianii.] These differences between $\mathrm{Rz}$ cells do not become apparent, however, until after $\mathrm{Rz}(5,6)$ processes contact the developing reproductive tissue. These observations suggest that some interaction between $\mathrm{Rz}(5,6)$ and the reproductive tissue is important in determining the segmental specializations of these neurons. This paper describes the results of experiments that test this possibility by ablating the reproductive primordia before these specializations arise and subsequently examining the morphology of $\mathrm{Rz}(5,6)$. Our results show that the segment-specific morphology of $\mathrm{Rz}(5,6)$ is at least partly determined by some form of interaction with their segmentally unique target tissue.

\section{Materials and Methods}

Animals. Embryos of Hirudo medicinalis were obtained from a laboratory breeding colony (Jellies et al., 1987).

Intracellular staining. Embryos were labeled intracellularly with HRP, as described in the preceding paper (Jellies et al., 1987). Usually both $\mathrm{Rz}$ cells were injected with HRP in each ganglion of interest. Since the quantification of our results was highly dependent on the quality of HRP staining, each filled cell was evaluated by examining its processes within the ganglion. The cells were rated by an observer who knew neither the ganglion (reproductive or standard) nor the type of preparation (experimental or control) that was being viewed. Each cell was given a score from 1 (poor) to 5 (excellent) for each of 3 characteristics.

1. Darkness-a measure of the amount of HRP reaction product formed. In lightly stained cells, fine processes may be missed.

2. Continuity -in poorly filled neurons, some fine branches may be discontinuous. In extreme cases, neurites may be represented only as discontinuous blobs or beads of reaction product.

3. Sharpness - a good fill presents a crisp image, having neurites with clearly defined edges, whereas in poorer fills, branches appear fuzzy, as though the dye had begun to leak from the cell.

Cells that received total rating of less than 11 were excluded from the 


\section{CONTROL}

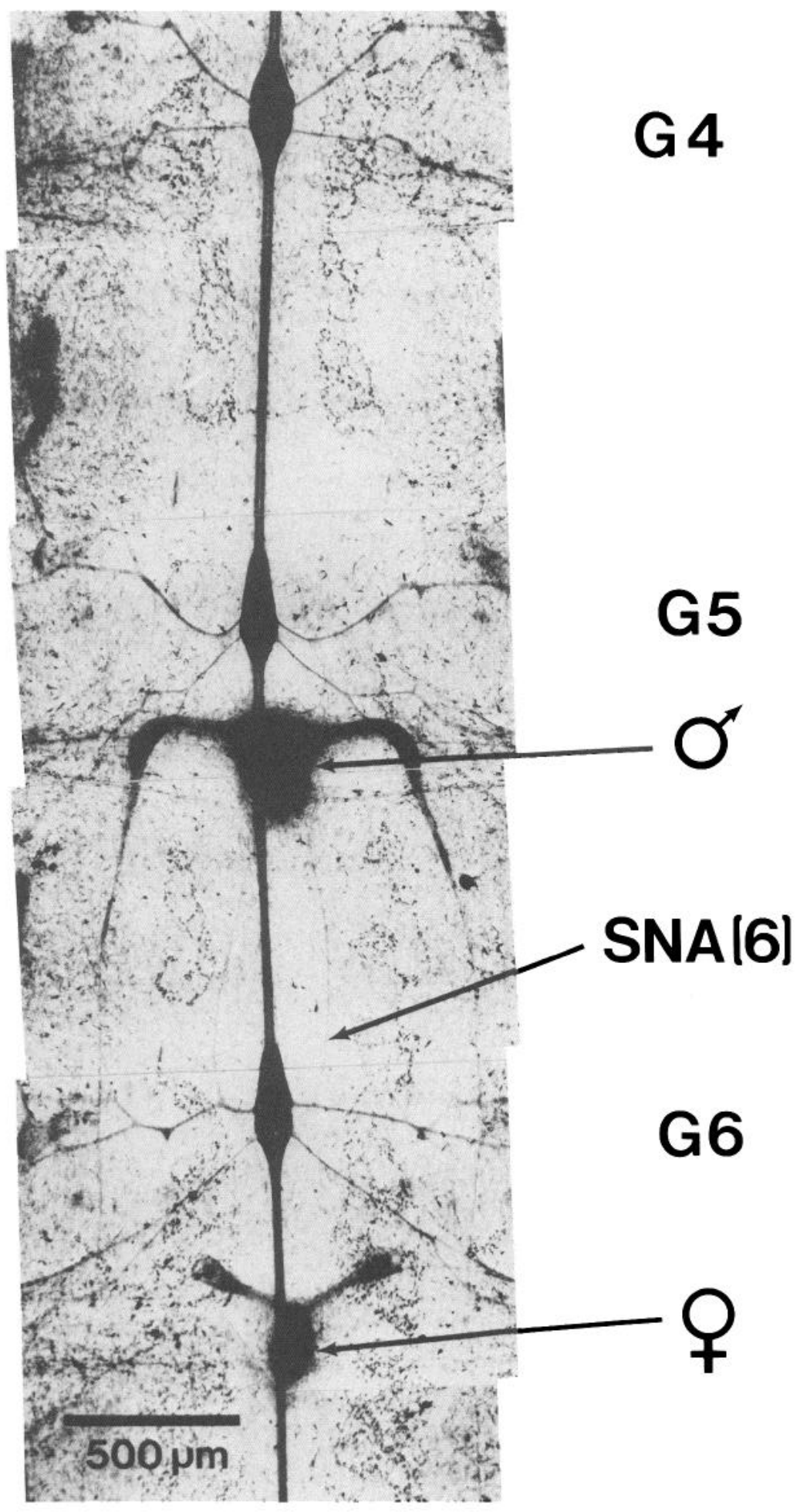

\section{ABLATED}

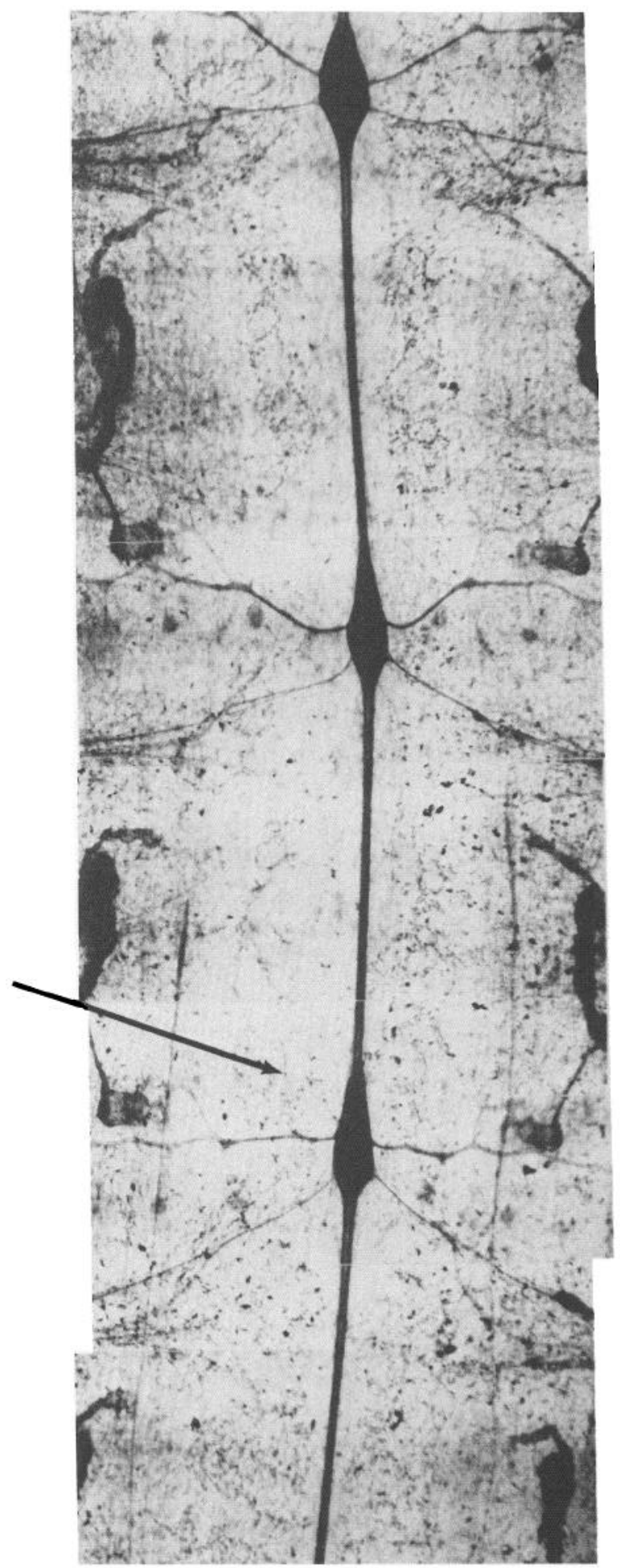

Figure 1. Midbody segments 4-6 in an unoperated control (left) and experimental embryo (right) at $20 \mathrm{~d}$ of development. The preparations were dissected and stained with gold chloride to enhance contrast (Humanson, 1979). Note the complete absence of reproductive structures in the "ablated" embryo and the normal appearance of nerves in the body wall. For example, the sex nerve from the anterior root of ganglion 6 [SNA(6)] can be seen in both preparations. The right $\mathrm{SNA}(6)$ in the "ablated" embryo is present but not apparent in this photograph. G4, G5, and $G 6$ are ganglia 4-6, respectively. Anterior is up in this and all subsequent figures; dorsal view. 
Table 1. Connective axon length, expressed as a percentage of total connective length

\begin{tabular}{lcc} 
Cell & $\begin{array}{l}\text { Axon length (\%) } \\
\text { (mean } \pm \text { SEM) }\end{array}$ & $n$ \\
\hline $\mathrm{Rz}(5,6)$ & & \\
$\quad$ Unoperated control & $0.4 \pm 0.3$ & 16 \\
$\quad$ Sham-operated control & $0.6 \pm 0.4$ & 12 \\
$\quad$ Experimental & $12.7 \pm 2.9$ & 35 \\
Standard $\mathrm{Rz}$ cells $[\mathrm{Rz}(3,8)]$ & $64.9 \pm 7.7$ & 18
\end{tabular}

Experimental $\mathrm{Rz}(5,6)$ values were significantly different (Student's $t$ test) from those of sham-operated $(p<0.05)$ and unoperated $(p<0.01)$ controls and of standard $\mathrm{Rz}(p<0.01)$. Standard $\mathrm{Rz}$ values were significantly different from those of sham-operated and unoperated controls $(p<0.01)$.

samples. (In an initial assessment of this rating scheme, cells that scored 11 and above were independently deemed consistently to be "good" to "excellent" fills.) Processes within the ganglion seemed to be completely filled in the select group. $\mathrm{Rz}$ cell processes extending outside of the ganglion into the connectives or body wall, on the other hand, almost always faded gradually, indicating incomplete filling.

Lucifer yellow injections were performed as described by Jellies et al. (1987).

Quantification of morphological characteristics. Density of neuropilar arborization was scored by digitizing camera lucida drawings of whole mounts of HRP-injected pairs of Rz cells with a Thunderscan device and software (Thunderware), using an Apple Macintosh computer and printer. A program written in Pascal (MacLanguage Series, TML Systems, and Pascal Extender, Invention Software) by one of the authors (C.L.), was used to measure the area of the ganglion taken up by processes of the cells, excluding the cell bodies and the major neurites of the cells. This quantity was expressed as a percentage of the total area of the ganglion. In 5 of 8 unoperated control $\mathrm{Rz}(5,6)$, only a single $\mathrm{Rz}$ cell was filled with HRP. In order that these might be compared with pairs of cells, a camera lucida drawing of the cell was copied xerographically onto a transparent sheet of plastic; this copy was reversed and overlaid on the original, being reflected across the midline of the ganglion. The outline of the ganglion was retained from the original drawing. A copy of this double image was digitized and measured as described above.

The length of axons in the interganglionic connectives was measured as described by Glover and Mason (1986; see Fig. 3), with axon length expressed as a percentage of connective length. Connective length was mcasurcd from the antcrior to the posterior ganglion edge. Connective axons were considered to be present when the axon length was $\geq 5 \%$ of the connective length.

The extent of peripheral branching was measured as the presence or absence of $\mathrm{Rz}$ cell branches in major nerves near the ganglion, because HRP injected into the cell body generally did not diffuse much beyond these branches. In the reproductive segments, the first major branch of the anterior nerve root of the ganglion is unique to that segment; in midbody segment 5 , this sex nerve extends posteriorly to the male reproductive tissue; while in midbody segment 6 , the nerve projects anteriorly, also to the male reproductive tissue in midbody segment 5. Experimental animals in which the reproductive tissue had been ablated were often also missing the segment-specific sex nerves that normally project to the reproductive tissue. Branching of processes was therefore scored only in those cases in which identification of the nerves was unambiguous.

Since unstained $R z$ cells could not always be unambiguously identified (especially in ganglia 5 and 6), and filling of the cells with HRP caused variable degrees of swelling of the soma, cell body diameters were not measured in these experiments.

Ablations and sham operations. Animals from a single cocoon (late day 9 to early day 10) containing 15 to 25 embryos were used for each ablation experiment. The results presented below were obtained from embryos from at least 10 different cocoons. At the beginning of each experiment, 2 cohorts from the cocoon were dissected, fixed, and subsequently stained with serotonin antiserum (Jellies et al., 1987) to assess the developmental age of the $\mathrm{Rz}$ cells at the time of the operations. There is generally little variation in the ages of embryos from a given cocoon. Experimental and sham-operated embryos were anesthetized in cold $8 \%$ ethanol/saline for 5-10 min prior to operations to eliminate
Table 2. Density of Rz neuropilar arhorization, expressed as a percentage of total ganglion area

\begin{tabular}{lcr} 
Cell & $\begin{array}{l}\text { Density of arbor }(\%) \\
(\text { mean } \pm \text { SEM) }\end{array}$ & $n$ \\
\hline $\operatorname{Rz}(5,6)$ & & \\
$\quad$ Unoperated control & $7.3 \pm 0.4$ & 8 \\
$\quad$ Sham-operated control & $8.6 \pm 0.4$ & 5 \\
$\quad$ Experimental & $10.5 \pm 0.5$ & 10 \\
Standard Rzcells $[\operatorname{Rz}(3,8)]$ & $11.3 \pm 0.5$ & 5
\end{tabular}

Experimental $\mathrm{Rz}(5,6)$ values were significantly different (Student's $t$ test) from those of sham-operated $(p<0.05)$ and unoperated $(p<0.01)$ controls, but not different from standard $\mathrm{Rz}(p>0.05)$. Unoperated and sham-operated controls were not significantly different from one another $(p>0.05)$ but were both different from standard $\mathrm{Rz}(p<0.01)$.

movements and relax the germinal plate. The embryos were placed ventral side up in chambers carved out of Sylgard-filled petri dishes, and illuminated from the side with fiber optics. The reproductive primordia could be seen as paired structures on either side of the midline within the living embryo (see Jellies et al., 1987, for development of the reproductive tissue). The reproductive tissue was sucked out with a hand-held micropipette made from a glass microelectrode broken to a tip diameter of approximately $50 \mu \mathrm{m}$ and connected to a vacuum flask. Tissue, including the reproductive tissue primordia, was removed from the ventral midline just posterior to ganglia 5 and 6 . Sham operations consisted of sucking out a comparable amount of tissue just anterior to the reproductive primordia, often including the nephridiopores of midbody segments 5 and 6 . Wounds healed after a few hours and the animals were allowed to develop for another 10-13 d. Shamoperated control animals were used to assess the effects of general tissue damage, tissue removal, and possible damage to the CNS and peripheral nerves. Almost all embryos $(>90 \%)$ survived the operations except in cases of generally ill health, when as many unoperated controls as experimental animals and sham-operated controls died.

\section{Results}

At 20-23 d of development, more than half the experimental animals (14/25) containcd no rcproductive structures in cither midbody segments 5 or 6 (Fig. 1). Since $\mathrm{Rz}(5)$ normally innervates only the male reproductive tissue in midbody segment 5 , 5 additional animals with female but no male reproductive tissue were scored as successful ablations when assessing $\operatorname{Rz}(5)$. $\operatorname{Rz}(5,6)$ from these 19 animals constituted the experimental group, which was compared to 3 other groups of Rz cells: standard $R z$ cells, represented by $R \_(3)$ and $R \_(8)$, taken from experimental and control animals; unoperated $\mathrm{Rz}(5,6)$ controls; and sham-operated $\mathrm{Rz}(5,6)$ controls. Cells from experimental animals with incomplete ablations $(6 / 25)$ were excluded from quantitative comparisons.

We examined the following 3 morphological characteristics of $\mathrm{Rz}$ cells filled intracellularly with HRP in 20-23-d-old embryos: length of axons in the connective, density of processes in the neuropil, and branching of processes in the body wall. $\mathrm{Rz}(5,6)$ differ significantly from standard $\mathrm{Rz}$ cells in these characteristics by $20 \mathrm{~d}$ of development (Glover and Mason, 1986; Jellies et al., 1987).

\section{Connective axons}

Standard Rz cells always had axons in the connective at 20-23 $\mathrm{d}$ of development $(18 / 18)$. In animals in which the reproductive tissue had been removed, 21 of $35 \mathrm{Rz}(5,6)$ extended axons into the connective; 12 of 21 had axons in both anterior and posterior connectives, and 9 of 21 had an axon in only one connective. These axons were situated laterally in the connective in the 


\section{A. Standard}

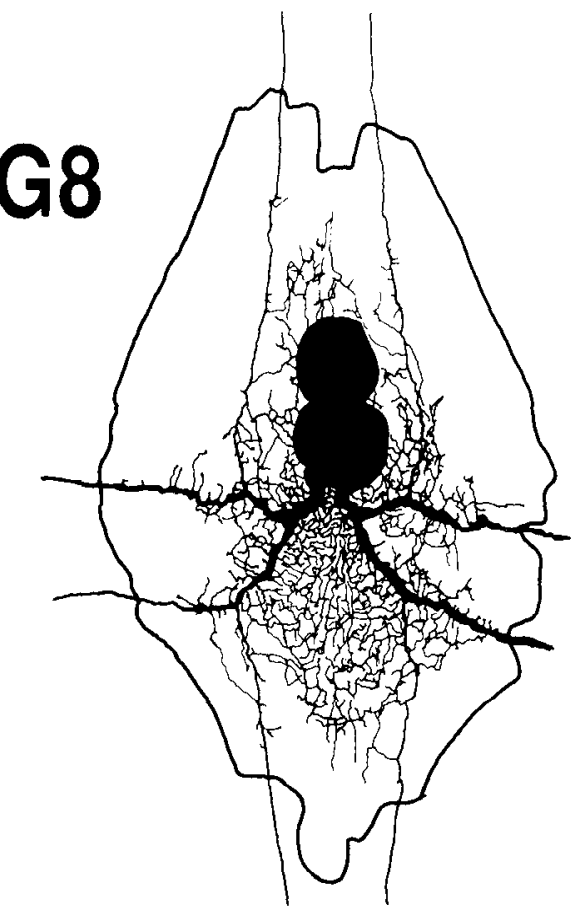

C. Unoperated

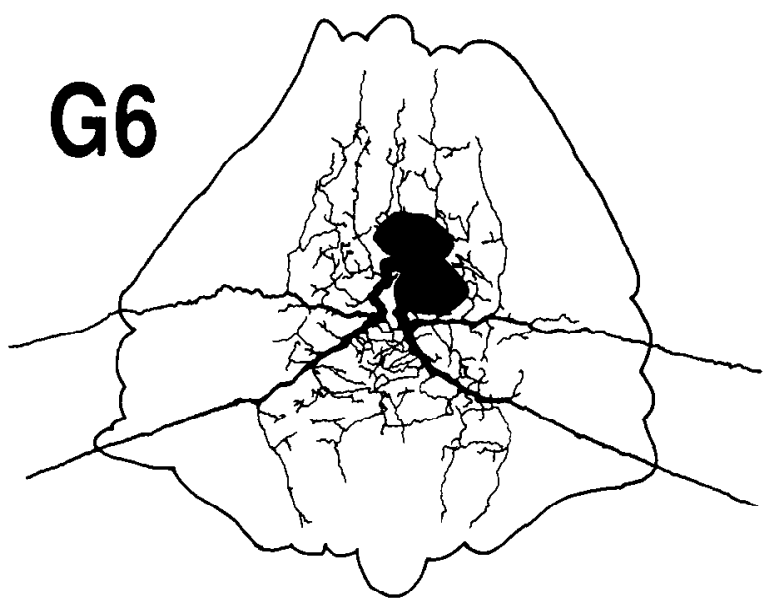

B. Experimental

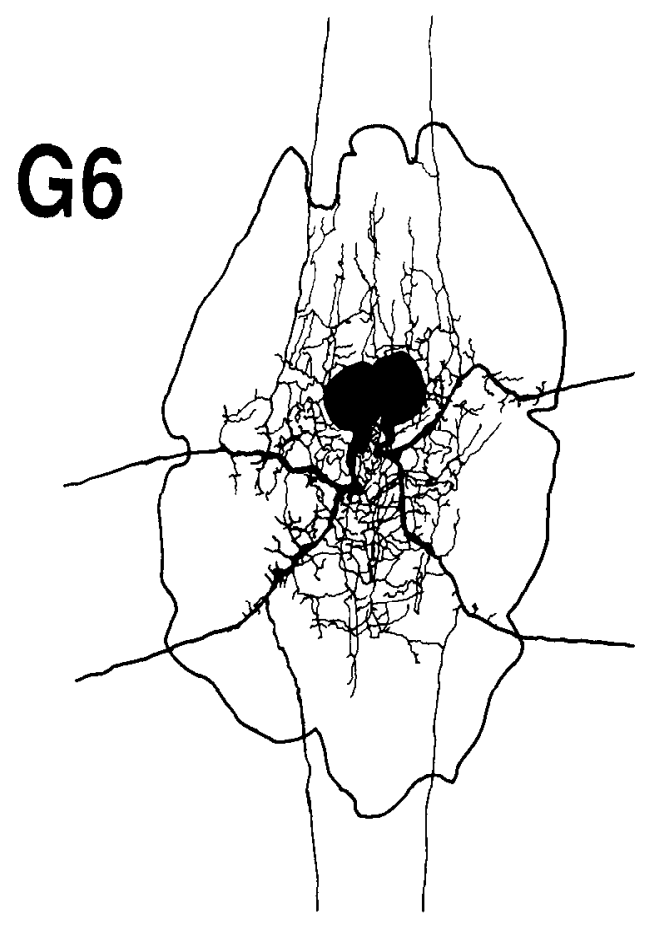

D. Sham-operated

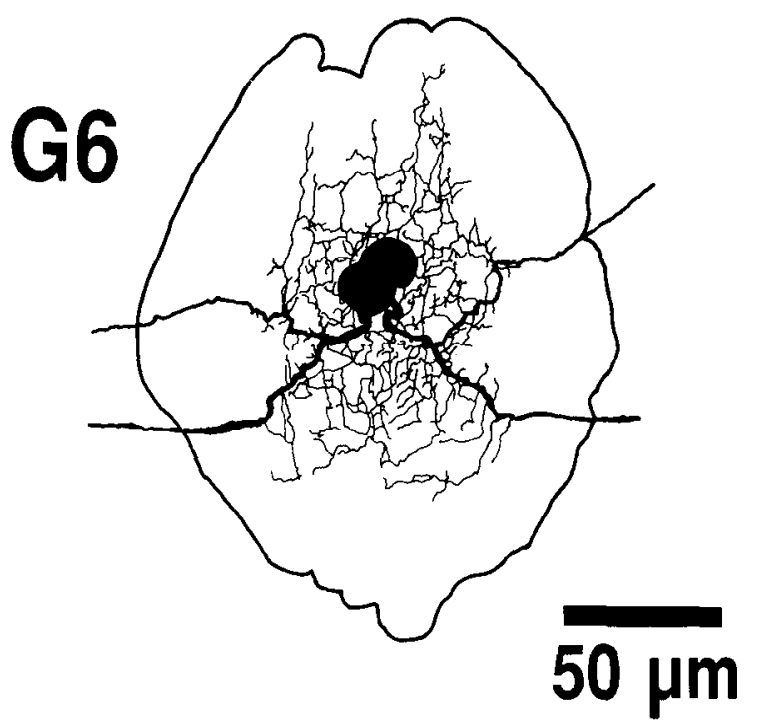

Figure 2. Neuropilar arborization of Rz cells in 20-23-d-old embryos. Camera lucida drawings of HRP-filled cells from representative ganglia. The dark outline indicates the edge of the ganglion as defined by neuronal cell bodies; some processes extend beyond the edge of the ganglion into the segmental nerves and interganglionic connectives. $A$, Standard $\mathrm{Rz}$ cells in $\mathrm{G} 8 . B, \mathrm{Rz}(6)$, experimental. $C, \mathrm{Rz}(6)$, unoperated control, $D, \mathrm{Rz}(6)$, sham-operated control.

normal position of axons of standard Rz cells. Only 2 of 16 cells in unoperated animals and 1 of 12 cells in sham-operated controls had axons in the connectives. As a percentage of connective length, the connective axons in $\mathrm{Rz}(5,6)$ of experimental animals were significantly longer than those of unopcratcd and sham-operated controls (Table 1). However, these axons were usually shorter than those of standard $\mathrm{Rz}$ cells. This could be accounted for, in part, by the fact that the connective axons of $\mathrm{Rz}(5,6)$ from experimental animals were usually somewhat finer than those of standard Rz cells; therefore, HRP might not have 

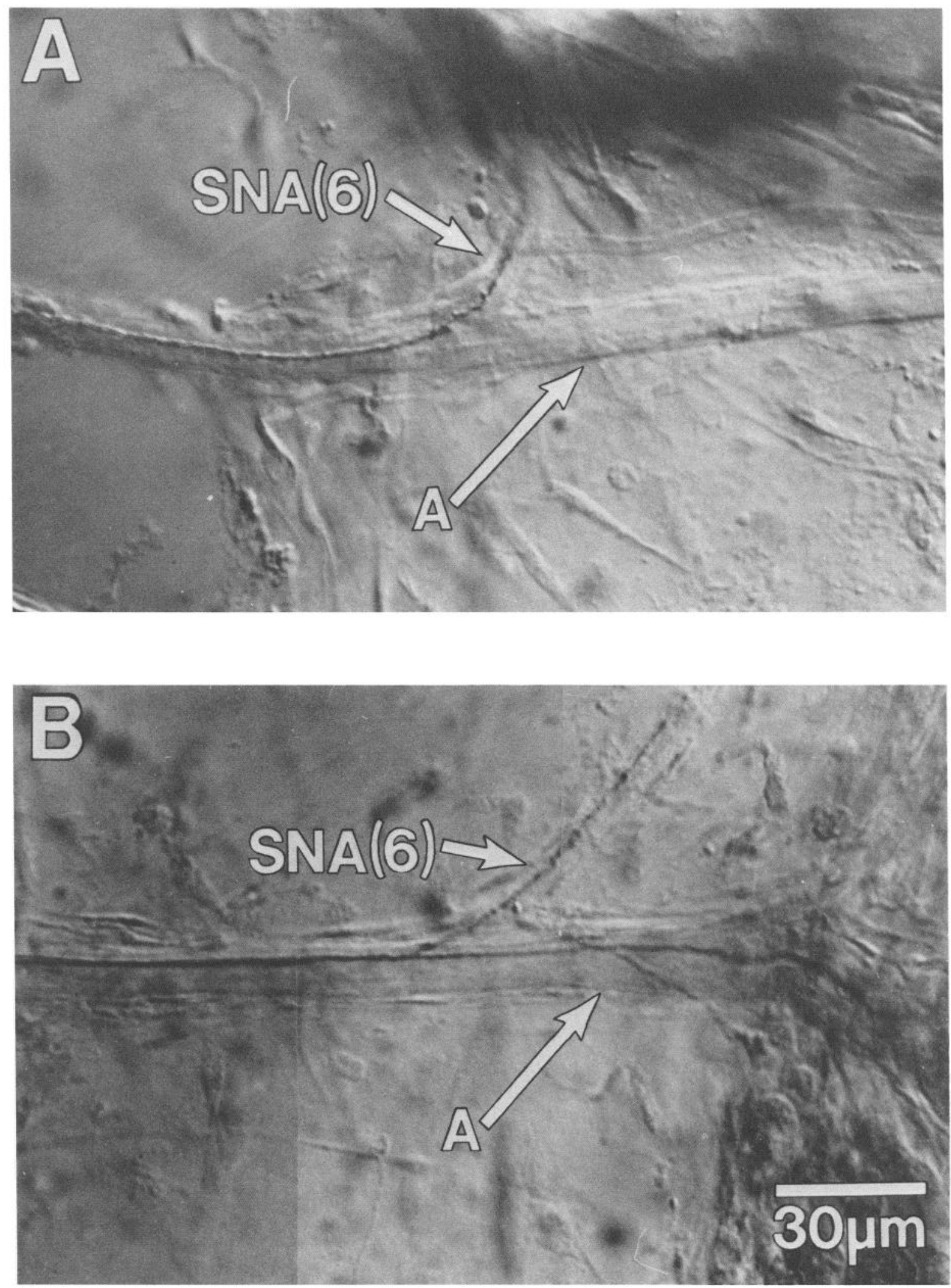

Figure 3. $\mathrm{Rz}(6)$ peripheral branching in unoperated control $(A)$ and experimental $(B)$ embryos at 20-23 d. The sex nerve of the anterior root of ganglion $6[S N A(6)]$ extends anteriorly to the male reproductive tissue in midbody segment 5 . Shown are processes of an HRP-filled $\mathrm{Rz}(6)$ at the anterior root $(A) / \mathrm{SNA}(6)$ branch point in both unoperated control and experimental embryos. 
diffused as readily within the smaller-caliber axons.

To determine the full extent of the branching pattern, $\mathrm{Rz}$ cells were filled with Lucifer yellow at about $13 \mathrm{~d}$ of development, a stage when this dye diffuses to the tips of most branches. $\mathrm{Rz}(5,6)$ in both experimental and control embryos had connective axons of varying lengths, as expected for this age (Glover and Mason, 1986). In one case, however, a process from $\mathrm{Rz}$ (5) in an experimental embryo extended to an adjacent ganglion (G4) and branched. $\mathrm{Rz}(5,6)$ in unoperated controls never extended processes so far into the adjacent segments.

\section{Neuropilar density}

Standard Rz cells in 20-23-d-old leeches filled the neuropil with many fine processes, whereas control $\mathrm{Rz}(5,6)$ had significantly fewer within the same region of neuropil (Jellies et al., 1987; Fig. 2). $R z(5,6)$ in experimental animals, however, had an arborization density significantly different from that in unoperated and sham-operated $\mathrm{Rz}(5,6)$, but not different from that in standard $\mathrm{Rz}$ cells (Fig. 2, Table 2). The region of arborization of $\mathrm{Rz}(5,6)$ in experimental animals covered about the same general extent as that of standard $\mathrm{Rz}$ cells and normal unoperated $\mathrm{Rz}(5,6)$. As with the length of connective axons, the density of neuropilar arborization was also somewhat variable; a few experimental $\mathrm{Rz}(5,6)$ had a neuropilar density that was more like that of control $\mathrm{Rz}(5,6)$ and some were intermediate.

\section{Peripheral innervation}

$\mathrm{Rz}(5,6)$ in unoperated controls seldom $(2 / 16)$ projected laterally beyond the sex nerve branch point in the anterior nerve by $20-$ $23 \mathrm{~d}$ of development, instead turning exclusively into the sex nerve (Fig. 3A). $\mathrm{Rz}(5,6)$ in sham-operated controls were comparable in this respect: only 2 of 12 extended processes laterally into the anterior nerve. In experimental animals, on the other hand, all $\mathrm{Rz}(5,6)$ examined $(10 / 10)$ extended processes laterally into the body wall at 20-23 d of development (Fig. 3B).

In particularly good fills of $\mathrm{Rz}(5,6)$ in experimental embryos, there was often considerable branching in the body wall, characteristic of the innervation by standard Rz cells and unlike that of $\operatorname{Rz}(5,6)$ in unoperated and sham-operated controls. Many $\mathrm{Rz}(5,6)$ in experimental embryos, for example, had considerable lengths of axon in the dorsal posterior nerve, indicating that these cells may have innervated dorsal body wall, a territory control $\mathrm{Rz}(5,6)$ never reached, even at the time of the furthest extent of their lateral growth.

\section{Partial ablations}

In 6 of 25 experimental animals, a portion of the reproductive tissue structures survived. The morphology of $\mathrm{Rz}(5,6)$ in these embryos was quite variable; some looked like $\operatorname{Rz}(5,6)$ from control embryos and others looked like standard $\mathrm{Rz}$ cells. In one embryo, a large portion of the male reproductive structure was innervated by $\mathrm{Kz} 5$ on only one side (Fig. 4). This cell looked like most $\mathrm{Rz}(5,6)$ in unoperated animals; it sent no branches latcrally in the postcrior or anterior nerves beyond the branch points of the sex nerves, and its entire peripheral arbor was confined to the partial male gonopore and duct. Its bilateral homolog, on the other hand, appeared not to innervate the displaced reproductive tissue and looked more like a standard $\mathrm{Rz}$ cell; it branched extensively in the body wall and the neuropil and extended an axon into one connective (Fig. 4). In embryos with partial ablations, $\operatorname{Rz}(5,6)$, that did not appear to contact the remaining reproductive tissue invariably branched in the body wall ( 6 cases); 5 of these cells also had connective axons.

\section{Discussion}

Evidence that target contact modifies $R z$ cell development All $\mathrm{Rz}$ cells initially appear to follow the same developmental pathway, leading eventually to apparent uniformity of structure and function for the $\mathrm{Rz}$ cells of most segments. The results of these experiments suggest that $\mathrm{Rz}(5,6)$ morphogenesis is interrupted by contact with a unique segmental target and diverted to a pattern of differentiation that is distinct from that of its segmental homologs. Development in the absence of the reproductive tissue leads $\mathrm{Rz}(5,6)$ to develop more like their segmental homologs - these cells extend axons into both the connectives and the body wall, and elaborate more processes within the central neuropil. That $\mathrm{Rz}(5,6)$ can develop like standard $\mathrm{Rz}$ cells when they fail to innervate reproductive tissue remaining from an incomplete ablation indicates that contact and not merely the presence of the target is important in this interaction.

Complementary experiments in which reproductive primordia were transplanted into standard segments to examine whether standard $\mathrm{Rz}$ cells could become like $\mathrm{Rz}(5,6)$ have shown that standard $\mathrm{Rz}$ cells will innervate ectopic reproductive tissue (Loer et al., 1985). This innervation is associated with decreased body wall innervation of those segments, suggesting that standard $\mathrm{Rz}$ cells make a target choice similar to $\mathrm{Rz}(5,6)$ when given the opportunity. Rz cells may conserve the total amount of peripheral arbor elaborated, allocating more to preferred targets; a similar mechanism has been suggested as regulating the central arbor of cricket cercal sensory neurons (Shepherd and Murphey, 1986). Whether additional morphological changes occur in standard $\mathrm{Rz}$ cells innervating reproductive tissue has not yet been examined. In 3 abnormal adult leeches, $\mathrm{Rz}$ cells associated with additional reproductive tissue in midbody segments 4 or 7 looked like $\mathrm{Rz}(5,6)$ (Macagno et al., 1986). $\mathrm{Rz}(4)$ and (7) in these animals may have responded to ectopic reproductive tissue and become like $\operatorname{Rz}(5,6)$; however, it is also possible that both the nervous system and the periphery in these animals were "reproductive" rather than standard.

In our experiments, early ablation of the reproductive tissue did not completely eliminate the development of differences in $\mathrm{Rz}(5,6)$. There are several possible reasons for this. (1) There may be intrinsic limitations to the ability of $\mathrm{Rz}(5,6)$ to express fully the standard pattern, such that they cannot attain the complete morphology of standard Rz cells. (2) Perhaps some $R z(5,6)$ had filopodial contact with the reproductive tissue at the time that the ablations were performed. Therefore, determination may have already occurred, restricting their ability to follow the standard developmental pathway. (3) Difficulties inherent in intracellular HRP injection limits our ability to see the full extent of many of the cells we inject. This could be the reason that the connective axons of $\mathrm{Rz}(5,6)$ were measured as shorter than those of standard Rz cells: the connective axons of $\operatorname{Rz}(5,6)$ in experimental embryos are usually finer than thosc of standard $\mathrm{Rz}$ cells, and so require a long diffusion time to fill. In most cases, the axons probably extended beyond the range that we could see, since they tended to fade out rather than end clearly and abruptly like those within the ganglion. Note that the lengths of axons of even standard $\mathrm{Rz}$ cells averaged less than $100 \%$, although we are quite certain that all standard $\mathrm{Rz}$ cells extend to the adjacent segment and perhaps beyond (see Glover and 


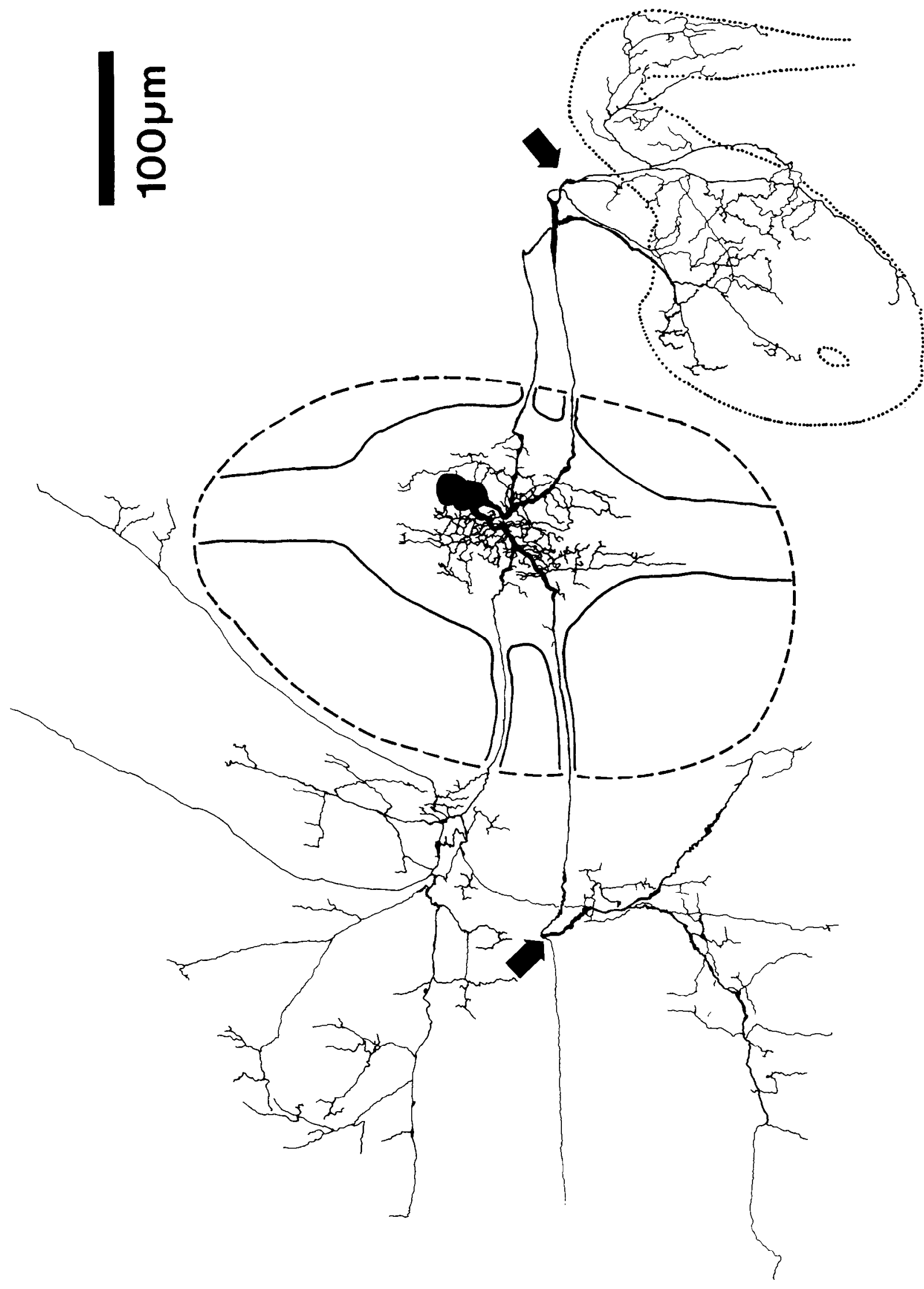

옿뼣

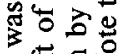

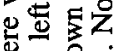

ङ

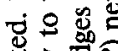

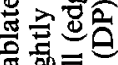

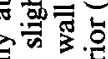

要要要要

즐.

更

击焉

ङ吉志

害专

놇

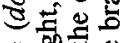

.

象号它

요율

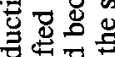

通哭

영.

o

总可

E.

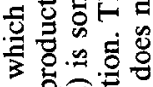

$\Xi$ 矛过.

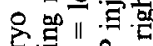

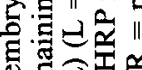

跑淧

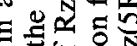

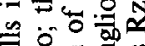

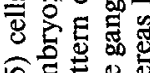

领帚焉

은 웡

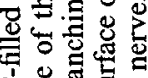

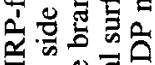

氠氖

용ㅎㅇ

उ 5

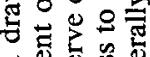

진

产导尔

푼 光

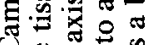

+ 记

$\forall 0$ 웡

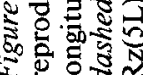


Mason, 1986; Jellies et al., 1987). (4) The changes we have described are not specific to the removal of the reproductive tissue, but are rather a nonspecific response to damage. Adult leech neurons are known to sprout when damaged (e.g., Muller and Scott, 1980). Also, some other leech neurons that normally retract interganglionic axons during embryogenesis will retain them if their axons to the body wall are cut (E. Macagno, personal communication). We have addressed these concerns with sham-operated controls in which body wall tissue near the reproductive tissue was removed in the same manner used for the ablations. This operation should cause much the same type of damage or potential damage to the CNS, peripheral nerves, and body wall that resulted from the ablations. $\operatorname{Rz}(5,6)$ from these sham-operated animals seldom differed in morphology from unoperated controls. Furthermore, whereas regenerated adult neurons often have numerous aberrant branches (Muller and Carbonetto, 1979), $\mathrm{Rz}(5,6)$ from the experimental group in this study had what appeared to be processes normal for standard Rz cells.

\section{Other segmental variations in leech development}

Some segmental differences in the leech must, of course, arise from differences in lineage. For instance, the reproductive tissue precursors arise only in midbody segments 5 and 6; nephridia and testis are also found only in a restricted number of segments; ganglia 5 and 6 contain almost twice as many neurons as do standard ganglia (Macagno, 1980). It should be noted that, since these neurons arise mostly postembryonically (Stewart et al., 1986), they are unlikely to be involved in the modification of segmentally homologous neurons in ganglia 5 and 6 during embryogenesis. There are some cases, however, in which competitive interactions between neurons may be important in the development of segmental differences in leech neurons. For example, early in embryogenesis, AP neurons have intersegmental axons that, in most segments, are later retracted. AP neurons adjacent to segments that do not contain AP neurons (either because of normal segmental differences or as a result of ablation) retain intersegmental axons and innervate the available peripheral territory (Gao and Macagno, 1987). Some similar form of competitive interaction may also be at work in causing expanded innervation of the body wall of midbody segments 5 and 6 by $\mathrm{Rz}(4)$ and $\mathrm{Rz}(7)$, respectively (Glover, 1984). Interestingly, nociceptive mechanosensory neurons in ganglia 5 and 6 also appear to innervate exclusively the reproductive tissue within their segment of origin (Johansen et al., 1984). These neurons might interact with reproductive tissue during embryogenesis in a way similar to that of $R z(5,6)$.

\section{Extrinsic influences on neuronal development in other organisms}

Modification of a neuron's functional identity by its peripheral target was first proposed as an explanation of seemingly appropriate movements of supernumerary limbs of salamanders following inncrvation by branches of motor ncrves from ncarby limbs (Weiss, 1936). Vertebrate motor neurons are now believed to be predetermined to innervate a particular target, selecting appropriate pathways (Tosney and Landmesser, 1985) and even fiber types (Thompson et al., 1984) without initial error. Although motor neuron type does not appear to be specified by the target, there is evidence that some vertebrate mechanosensory neurons may acquire their identity from the tissue they innervate (Frank and Westerfield, 1982). Neural crest derivatives are well known for their plasticity: when moved to ectopic locations, they migrate along paths and synthesize transmitters that are appropriate to their new environment, rather than to their initial site of origin (Le Douarin et al., 1981).

Sensory neurons that have been genetically or surgically transplanted into ectopic sites in insects do not appear to change their projections and connections to be appropriate for their new location (Deak, 1976; Stocker and Lawrence, 1981; Ghysen et al., 1983; Anderson, 1985). Experiments in Manduca have shown that larval sensory neurons retain their larval morphology even within a pupal CNS, and do not make appropriate pupal connections (Levine et al., 1986). On the other hand, while these same neurons can attain a pupal morphology in a larval CNS, they are unable to make appropriatc pupal conncctions until the CNS undergoes metamorphosis as well (Levine, 1986). Furthermore, in C. elegans, despite a highly determinate lineage, 2 mechanosensory neurons that normally exhibit different morphologies and connectivities will each acquire the characteristics of the other when moved experimentally to the other's appropriate location (Chalfie et al., 1983). Interestingly, a sex-specific muscle in the abdomen of Drosophila seems to be determined not by the sex of the myoblasts from which it forms, but rather by the sex of the neurons that innervate it (Lawrence and Johnston, 1986).

The results of such experiments and our own show that a highly determinate lineage is not indicative of a lack of important cellular interactions in the development of invertebrate nervous systems (e.g., Murphey, 1986). We have shown that an identified neuron changes both its central and peripheral morphological phenotype in response to contact with a particular peripheral target. Such interactions are likely to be necessary to construct the complex nervous systems of both vertebrates and invertebrates.

\section{References}

Anderson, H. (1985) The development of projections and connections from transplanted locust sensory neurons. J. Embryol. Exp. Morphol. 85: 207-224.

Baker, B., and K. Ridge (1980) Sex and the single cell: On the action of major loci affecting sex determination in Drosophila melanogaster. Genetics 94: 383-423.

Bentley, D., and H. Keshishian (1982) Pathfinding by peripheral pioneer neurons in grasshoppers. Science 218: 1082-1088.

Chalfie, M., J. N. Thompson, and J. E. Sulston (1983) Induction of neuronal branching in Caenorhabditis clegans. Science 221: 61-63.

Deak, I. I. (1976) Demonstration of sensory neurons in the ectopic cuticle of spineless-aristapedia, a homeotic mutant of Drosophila. Nature 260: 252-254.

Doe, C. Q., and C. S. Goodman (1985) Early events in insect neurogenesis. II. The role of cell interactions and cell lineage in the determination of neuronal precursor cells. Dev. Biol. 111: 206-219.

Frank, E., and M. Westerfield (1982) The formation of appropriate central and peripheral connexions by foreign sensory neurones of the bullfrog. J. Physiol. (Lond.) 324: 495-505.

Gao, W.-Q., and E. R. Macagno (1987) Extension and retraction of axonal projections by some developing neurons in the leech depends upon the existence of neighboring homologues. II. The AP and AE neurons. J. Neurobiol. 18: 295-313.

Ghysen, A., J. Renaud, and D. Santamaria (1983) Segmental determination of sensory neurons in Drosophila. Dev. Biol. 99: 7-26.

Glover, J. C. (1984) Structure, function and development of serotonincontaining neurons of the leech. Doctoral disscrtation, Univcrsity of California, Berkeley.

Glover, J. C. (1987) Serotonin storage and uptake by identified neurons in the leech Haementeria ghilianii. J. Comp. Neurol. 256: 117-127. 
Glover, J. C., and A. Mason (1986) Morphogenesis of an identified leech neuron: Segmental specification of axonal outgrowth. Dev. Biol 115: 256-260.

Ho, R. K., and C. S. Goodman (1982) Peripheral pathways are pioneered by an array of central and peripheral neurones in grasshopper embryos. Nature 297: 404-406.

Humanson, G. L. (1979) Animal Tissues Techniques, 4th Ed., W. H. Freeman, San Francisco.

Jellies, J., C. M. Loer, and W. B. Kristan, Jr. (1987) Morphological changes in leech Retzius neurons after target contact during embryogenesis. J. Neurosci. 7: 2618-2629.

Johansen, J., S. Hockfield, and R. D. G. McKay (1984) Distribution and morphology of nociceptive cells in the CNS of three species of leeches. J. Comp. Neurol. 226: 263-273.

Kuwada, J. Y. (1986) Cell recognition by neuronal growth cones in a simple vertebrate embryo. Science 233: 740-746.

Lawrence, P. A., and P. Johnston (1986) The muscle pattern of a segment of Drosophila may be determined by neurons and not by contributing myoblasts. Cell 45: 505-513.

Le Douarin, N. M., J. Smith, and C. S. Le Lievre (1981) From the neural crest to the ganglia of the peripheral nervous system. Annu. Rev. Physiol. 43: 653-671.

Levine, R. B. (1986) Hormonal control of neuronal reorganization during insect metamorphosis. Soc. Neurosci. Abstr. 12: 928.

Levine, R. B., J. W. Truman, D. Linn, and C. M. Bate (1986) Endocrine regulation of the form and function of axonal arbors during insect metamorphosis. J. Neurosci. 6: 293-299.

Loer, C. M., J. Jellies, and W. B. Kristan, Jr. (1985) The possible role of target interactions in the development of segment-specific differences of an identified neuron. Soc. Neurosci. Abstr. 11: 957.

Lopresti, V., E. R. Macagno, and C. Levinthal (1973) Structure and development of neuronal connections in isogenic organisms: Cellular interactions in the development of the optic lamina of Daphnia. Proc. Natl. Acad. Sci. USA 70: 433-437.

Macagno, E. R. (1980) Number and distribution of ncurons in lecch segmental ganglia. J. Comp. Neurol. 190: 283-302.
Macagno, E. R., A. Peinado, and R. R. Stewart (1986) Segmental differentiation in the leech nervous system: Specific phenotypic changes associated with ectopic targets. Proc. Natl. Acad. Sci. USA 83: 27462750 .

Muller, K. J., and S. Carbonetto (1979) The morphological and physiological properties of a regenerating synapse in the C.N.S. of the leech. J. Comp. Neurol. 185: 485-516.

Muller, K. J., and S. A. Scott (1980) Removal of the synaptic target permits terminal sprouting of a mature intact axon. Nature 283: 8990

Murphey, R. K. (1986) The myth of the inflexible invertebrate: Competition and synaptic remodelling in the development of invertebrate nervous systems. J. Neurobiol. 17: 585-591.

Raper, J. A., M. Bastiani, and C. S. Goodman (1983) Pathfinding by neuronal growth cones in grasshopper embryos. II. Selective fasciculation onto specific axonal pathways. J. Neurosci. 3: 31-41.

Shepherd, D., and R. K. Murphey (1986) Competition regulates the efficacy of an identified synapse in crickets. J. Neurosci. 6: 31523160 .

Stewart, R. R., D. Spergel, and E. R. Macagno (1986) Segmental differentiation in the leech nervous system: The genesis of cell number in the segmental ganglia of Haemopis marmorata. J. Comp. Neurol. 253: 253-259.

Stocker, R. F., and P. A. Lawrence (1981) Sensory projections from normal and homeotically transformed antennae in Drosophila. Dev. Biol. 82: 224-237.

Stuart, D. K., S. S. Blair, and D. A. Weisblat (1987) Cell lineage, cell death, and the developmental origin of identified serotonin- and dopamine-containing neurons in the leech. J. Neurosci. 7: 1107-1122.

Thompson, W. J., L. A. Sutton, and D. A. Riley (1984) Fibre type composition of single motor units during synapse elimination in neonatal rat soleus muscle. Nature 309: 709-711.

Tosney, K. W., and L. T. Landmesser (1985) Specificity of early motoneuron outgrowth in the chick embryo. J. Neurosci. 5: 2336-2344.

Weiss, P. A. (1936) Sclectivity controlling the central-pcripheral rclations in the nervous system. Biol. Rev. 11: 494-531. 